\title{
ARQUEO-MONTAGEM DA AULA
}

\author{
Sônia Regina da Luz Matos \\ Betina Schuler
}

\section{Resumo}

Neste artigo ensaiado, opta-se por operar com uma arqueo-montagem, como que perguntando pelo arquivo tratando-se da aula no presente. A partir disso, buscamos alguns funcionamentos da aula neste contemporâneo de ataque a escolas e professores, de super aceleração e utilitarismo pragmático e, ainda, atravessado pela pandemia do novo coronavírus. Com esses sintomas, artistamos algumas possibilidades de aula como que fazendo uma montagem entre a educação, o cinema, a fotografia e a filosofia para criarmos outras composições possíveis da aula no presente. Para tanto, convidamos algumas companhias, tais como Deligny (1913-1996) e Sêneca (65 d.C.), para pensarmos o nosso presente.

Palavras-chave: arquivo; aula; educação

\section{THE ARCHEO-ASSEMBLAGE OF A CLASS}

\begin{abstract}
In this rehearsed paper, we have chosen to work with an archeo-assemblage, as if asking for the archive by addressing the classes in the present. From there, we have sought for some ways that classes have functioned in this contemporary times of attack to schools and teachers, of superacceleration and pragmatic utilitarianism, also crossed by the pandemic of the new coronavirus. With these symptoms, we have created some possibilities of classes, as if it were an assemblage of education, cinema, photography and philosophy in order to devise other possible compositions of classes in the present time. Hence, we have brought some contributions from Deligny (1913-1996) and Seneca $(65 \mathrm{dc})$ to think about our present time.
\end{abstract}

Keywords: archive; class; education

\section{ARQUEO-MONTAJE DEL AULA}

\section{Resumen}

En este artículo ensayado, se opta por operarcon un arqueo-montaje, como preguntando por el archivo tratándose del aula en el presente. A partir de esto, buscamos un cierto funcionamiento del aula en este contemporáneo de ataque a escuelas y profesores, de súper aceleración y utilitarismo pragmático y, además, atravesando por la pandemia del nuevo coronavirus. Con estos síntomas, creamos algunas posibilidades de aula, como realizando un montaje entre la educación, el cine, la fotografía y la filosofía para crear otras composiciones posibles de aulas en el presente. Para eso, hemos traído algunas aportaciones de Deligny (1913-1996) y Séneca (65 d.C.) para pensar en nuestro tiempo presente.

Palabras clave: archivo; aula; educación 


\section{ALGUM INÍCIO}

Preferir. Verbo com potência de arquivista de cartas mortas, cartas perdidas (MELVILLE, 2008). Preferir gostar das pessoas a amar a humanidade; preferir o inferno do caos ao da ordem, preferir o tempo dos insetos (SZYMBORSKA, 2011). Mulheres mais de preferências do que de conclusões.

Preferimos uma arqueo-montagem a uma epistemologia que divide o mundo em verdadeiro e falso, tendo a ciência os bons métodos para tal veridicção. Preferimos perguntar pela sintomatologização do contemporâneo, perguntar pelos sintomas que nos atravessam, perguntar pelo arquivo. E perguntar pelo arquivo não significa perguntar pelas condições de validade do discurso pedagógico, por exemplo, mas pelas condições de possibilidade, pelas condições de realidade dos enunciados e por suas emergências (FOUCAULT, 2002). E, se há algum a priori, só poderia ser histórico. Não a história das origens e das totalidades, mas a história das máscaras, da exterioridade, das emergências e do acidente (FOUCAULT, 2003). Que espaço limitado de comunicação é este da educação brasileira no presente? Esse questionamento, que pergunta pelo arquivo, não examina o acumulado na memória, a comprovação do passado ou as instituições que os guardariam. Preferimos perguntar pela lei do que pode ser dito, ou seja, as condições históricas de possibilidade dos enunciados (FOUCAULT, 2002).

Por isso, não nos interessa uma estrutura, uma fórmula, mas uma problematização de nossos modos de existência, destacando a regularidade dos enunciados, perguntando pelos lugares no discurso para tais enunciações e para os meios institucionais, uma vez que "[...] cada enunciado é uma multiplicidade: uma multiplicidade e não uma estrutura ou um sistema” (DELEUZE, 1998, p. 24).

O que é possível falarmos em educação no presente? O que é possível colecionarmos para reutilizarmos de alguma maneira? Quais as formas de memória? Quais as formas de visibilidade e as formas de enunciação em se tratando da aula no presente? $O$ que nos interessa não é o que é uma aula nestes tempos do presente. O que nos interessa é perguntar pelo seu sistema de funcionamento. E aqui não se quer a descrição exaustiva e totalitária, o que seria impossível. Queremos descrever algumas regiões, alguns fragmentos, e também inventar algumas outras possibilidades de vida e pensamento.

Convidamos, então, algumas boas companhias, tal como Deligny e Sêneca, para nos potencializar o pensar quando perguntamos pela aula como problematização do presente. Para tanto, criamos a aula pelo procedimento dos vagabundos eficazes e criamos a aula a partir de conselhos por cartas para perguntarmos pela aula no presente.

\section{UMA AULA}

Afetados ${ }^{1}$, em afecção (DELEUZE, 2009), pelo grotesco e veloz pandêmico, pelo controle de vivos e mortes, atingindo os corpos que insistem, ainda, por perguntar pela aula: e a aula?

Disparador da pergunta vem da estranheza ${ }^{2}$ que primeiro nos afeta. $\mathrm{O}$ isolamento para alguns, para poucos e para tantos; evidencia-se a estranheza constantemente, com a (im)possibilidade de apreensão da aula. Coube-nos perguntar por ela diante da aproximação

\footnotetext{
${ }^{1} \mathrm{Um}$ corpo que aumenta e diminui a potência de agir, encontros.

2 Em um curso de pedagogia, um dos estudantes elabora essa palavra para expressar a ideia de aula síncrona que experimentou durante o primeiro semestre de 2020.
} 
das evidências científicas que cercam - censuram - os discursos institucionais em educação; queremos dizer que esse cerceamento pouco nos causa estranheza. Bem, se a evidência científica e midiática da aula for elevar a uma relação pela via do controle online e/ou offline, grava-se a aula como cupom desta medida mercadológica cientificista.

Pela estranheza, ainda se deslocam as (im)possibilidades de apreender sobre a aula; e por isso escolhemos fazer um movimento de captura do discurso que nos invadia a cada aula, agora nominada como aula síncrona, em que o corpo é invadido pela tela. As estranhezas que conduz a nova ordem da aula. Ela sempre escapa. Na tela aula, fecham-se a câmera e o áudio, e escreve-se no chat da plataforma Google Meet, no Teams ou no Zoom. Ouvese e vê-se a voz? Sem elipse, dispara a pergunta sobre a aula, pergunta pelo discurso da aula: online e offline.

Os corpos também apreendem o sintoma das institucionalizações da didática; os corpos produzem e são produzidos incessantemente pelos discursos. A força do discurso da universalidade, determinante da ordem natural e eterna do ensino dos conhecimentos enciclopédicos, universal e metodicamente professados para serem replicados, também não cessa o discurso sobre o arquivo-aula, diante de tantas lives com prescrições em tempos de ensino remoto. Vocabulário e glossário empreendem-se para tratar de dar nova ordem à aula pela via do denominado ensino remoto: aula híbrida, aula remota, aula síncrona, aula YouTube, aula live, entre outras. E aqui não há denúncia da ordem dicotômica do certo ou do errado; trazemos apenas problematizações sobre os sintomas que nos atravessam no presente.

Perguntar-se sobre a aula nos faz eleger um elemento da arqueo-montagem, a desmontagem, problematizando um de seus discursos positivistas, o tratado sistemático de Comenius (1592-1670). Em Didática Magna, indicam-se os Principios em que se fundamenta a solidez. no ensinar e no aprender. Dos dez princípios, queremos retirar somente um, o primeiro, que traz que, em se tratando da aula, "[...] se só forem estudados, assuntos de inquestionável utilidade" (COMENIUS, 2002, p. 185). Solidificada nesse contorno de aula, "[...] a arte de ensinar não exige mais que uma disposição tecnicamente feita do tempo, das coisas e do método" (COMENIUS, 2002, p. 127). Tal exatidão discursiva eleva-se ao nível da metáfora do professor, o operário-executor de um método prévio e absolutamente resolvido, ou simplesmente como o tipógrafo-mestre da instrução escolar (COMENIUS, 2002). Pelas forças de modo de prescrição, eleva-se a uniformidade escolar como tipografia viva, sem que cada professor possa tirar da própria vida o que deve ensinar (COMENIUS, 2002). Essa perspectivada aula tem a necessidade de estabilizar o conhecimento sobre ela rapidamente. Mesmo que tal orientação pedagógica tenha vozes seculares, ela se atualiza pelas forças vertiginosas (MATOS, 2009) da didática geral: selecionar conteúdos e objetivos, prever recursos inovadores/tecnologias, aplicar instrumentos avaliativos, apontar o progresso (HAYT, 2006) das competências da Base Nacional Comum Curricular, online e ou offline.

Sem calar o tema da aula, a autora Corazza (1996) deixa-nos rastros discursivos, um tipo de arqueo-montagem da didática, em um de seus clássicos textos. O material que tematiza a aula encontra-se na produção do Programa de Atividades de Aperfeiçoamento Pedagógico PAAP, sobre a Melhoria do Ensino e Capacitação Docente dos Professores Universitários, que pergunta:

O que diriam os indagadores(as) desta pergunta: 'Como dar uma aula?' e se contemporaneamente, lhes respondêssemos que não sabemos como dar uma aula [...]. Que não existe uma resposta absoluta, possível de ser universalizada, para esta pergunta? Que não há nenhuma ciência objetiva, 
nenhuma prática discursiva, nenhum campo conceitual que possibilite essencializar o que seja ou o quê/como deve ser uma aula. (CORAZZA, 1996, p. 62).

Diante de tamanha indagação, os golpes dessa entonação mudam a pergunta. Uma vez que se exclui o peso de escrever sobre a aula, dela se retira uma unidade de significação representativa e se pergunta por uma aula, o que se passa em uma aula? Uma aula não se repete nunca; ela tem a potência do instante, do encontro consigo e com o outro, da atualização, porque "[...] não há aula que não abale as representações, arrastando-nos até os seus limites, avesso ou fora" (HEUSER, AQUINO, CORAZZA, 2018, p. 15).Nas bordas de uma aula, operam visões audíveis de uma heterogeneidade de signos que, por estarem disjuntos em meio ao rizoma, entre acaso e acontecimento, não podem ser úteis para a prescrição sobre a aula, seja ela online e ou offline. A aula, em sua heterogeneidade de signos, mistura-se, estranha-se, vive em meio ao povoamento da solidão (MATOS, 2016), afetandose pela possibilidade das amizades conselheiras que destinamos para problematizar o atual arquivo da aula: Deligny e Sêneca.

\section{SINTOMAS DE AULA: ARQUEO-MONTAGEM E A PROBLEMATIZAÇÃO DO PRESENTE}

Preferimos um roubo da arqueologia de Michel Foucault (2002) e da montagem de Didi-Huberman (RODRIGUES, 2020) para elaborarmos uma arqueo-montagem da aula. $\mathrm{Da}$ arqueologia, tomamos emprestado o procedimento da escavação das camadas dos discursos já ditos, descrevendo-os em suas possibilidades, regularidades e deslocamentos (FOUCAULT, 2002). A partir disso, o que nos interessa são as condições de existência dos discursos. Buscamos mostrar como a prática política faz parte das condições de emergência e do funcionamento do discurso pedagógico que toma a aula como objeto. Para isso, procuramos a descrição dos saberes, e não a origem de uma teoria; buscamos a descrição de funcionamentos de aula no presente e alguns aconselhamentos pela via da amizade para pensarmos o presente.

O que quer uma escrita que pergunta pelos sintomas em vez de perguntar o que é uma aula? Trata-se, talvez, de uma escrita que opera por montagem e que, portanto, se questiona pelos gestos políticos, artísticos e filosóficos implicados. Assim que tomar o conceito de montagem pode ser uma brecha importante, pois incluiu o procedimento da desmontagem, que se interroga pelos rastros, pelos sintomas do nosso tempo, para problematizar o que estamos fazendo de nós mesmas. "A desmontagem é um movimento de sintomatologização, de interrogação da própria historicidade para pensar que imagens se estão produzindo, mas também movimentos éticos, estéticos e políticos de montagem de outras possibilidades" (RODRIGUES, SCHULER, 2019, p. 33). A montagem surge como possibilidade de tomarmos uma forma para pensarmos a diferença em educação.

Didi-Huberman (2011, p. 70) fala da importância de uma relação inquieta com o seu tempo, de interrogar o contemporâneo, ou seja, “[...] dar os meios de ver aparecerem os vagalumes no espaço da superexposição, feroz, demasiado luminoso, de nossa história presente". Por isso, a montagem não se trata de simples reagrupamentos, estando implicado na produção da diferença, possibilitando outros movimentos de vida e de pensamento, o que necessita também de certo gesto de interrupção da velocidade no nosso presente.

Em tempos de ataque à escola, chamada de obsoleta e inútil, outros enunciados, a partir de um discurso empresarial, atravessam-na desde o final do século XX, operando com 
os alunos como clientes que precisam ser agradados em seus interesses individuais. Neste presente super acelerado, em que a passividade está justamente em não parar, em que se compete consigo mesmo até a exaustão (HAN, 2017), quais os atravessamentos para a educação? Neste presente em que a opinião substitui o exercício do pensamento (SIBILIA, 2012), em que o marketing e o design têm a ensinar aos professores como organizar suas aulas como youtubers, quais as implicações para a aula? Neste presente em que o estudo e a ação concentrada se deslocam para uma dispersão hiperconectada, em que pouco espaço há para a conversação, qual o lugar para a criação de sentidos partilhados e para a duração de algo? Neste presente em que os alunos-clientes "consomem" a escrita e a leitura e somente o que lhes é atraente no momento, como pensar a experiência? Neste presente em que se deixa de perguntar pela finalidade da educação em prol do elogio de metodologias instrumentais rapidamente aplicáveis, em que a aula se transforma em espetáculo (e não o da arte, mas o do marketing) nesta agitação contemporânea, quais as possibilidades para o exercício do pensamento?

Em tempos, como diria Walter Benjamin (2012), de esmaecimento da narratividade que pode ser transmitida como um anel para as próximas gerações. Em tempos em que as humanidades, as bibliotecas, as universidades, vêm sendo descritas como atrasadas e inúteis, como nos mostra Ordine (2016). Em tempos em que o neoliberalismo transforma as escolas em empresas em nome de um pragmatismo e eficiência (LAVAL, 2019), fazendo-nos acreditar que se está reformando a escola, quando se está liquidando com a educação, reduzindo-a a um pacote de competências básicas. Em tempos de uma "[...] tagarelice do consenso midiático" (LAZZARATO, 2014 p. 125), na qual "[...] empresas e o Estado, substituindo o professor ou o confessor, prescrevem como se conduzir" (LAZZARATO, 2014, p. 195), como problematizar os nossos modos de escravidão no presente, fortemente marcados por uma stultitia espetacularizada?

Daí a ideia de arqueo-montarmos funcionamentos de aulas no contemporâneo atravessados pela pandemia do novo coronavírus, mas também atravessados por todo um léxico empresarial nessa governamentalidade neoliberal que invade escolas e universidades. E isso para dar visibilidade aos regimes de verdade que nos cercam e nos produzem e, ao mesmo tempo, para conseguirmos criar outras composições possíveis em educação nesse processo de montagem de heterogeneidade de signos com a literatura, a filosofia, o cinema e a fotografia. Além disso, em tempo de culto ao novo e à inovação, percebe-se a importância da conversação com alguns clássicos. Uma conversa com os mortos para pensarmos a vida, pois precisamos de boas companhias e podemos tê-las via texto. Podemos escutá-las com os ouvidos do presente para fazermos outras coisas com elas. Isso porque "[...] o que você diz tem ressonância, o que silencia tem um eco, de um jeito ou de outro, político" (SZYMBORSKA, 2011, p. 77).

\section{CONVERSAÇÕES COM AS COMPANHIAS: DELIGNY E SÊNECA}

Sêneca (2018), na carta 62, escreveu sobre as boas companhias, sejam elas do século ou local que forem. Aqui tomamos a conversação com os mortos como uma possibilidade de pensarmos o nosso presente, atualizando algumas discussões, para ainda podermos pensar

\footnotetext{
${ }^{3}$ Conceito criado no grupo de pesquisa coordenado pela Prof ${ }^{a}$. Betina Schuler para pensarmos essa stultitia contemporânea que se orgulha de sua razão vulgar, de não ter argumentos e que funciona performaticamente buscando visibilidade com todo tipo de preconceito, covardia e ressentimento, dispensando a moral em nome da técnica.
} 
na aula. Convidamos Deligny e Sêneca para ajudarem-nos a tomar a problematização da aula em tempos de uma stultitia espetacularizada, em tempos em que estamos por demais acelerados e agitados para que algo faça morada, para que algo permaneça, para que algo seja digno do nome de experiência. O conceito de stultitia, operado por Sêneca e retomado por Foucault (2011) aqui se faz importante como uma problematização desses refletores que nos cegam em nosso presente. Conforme traz Sêneca (2018, p. 133) na carta 37 a Lucílio: “[...] a indignidade não está em 'irmos', mas em 'sermos levados', em perguntarmos de súbito, surpreendidos, no meio de um turbilhão de acontecimentos: 'mas como é que eu vim parar aqui"”.

\section{Conselhos de Deligny por meio dos vagabundos eficazes}

Fernand Deligny preferia ser chamado mais de poeta a qualquer outra denominação. Determinado a viver em isolamento com jovens e crianças denominados autistas e marginais, recusa-se ao excesso de fala sobre educação e faz suas expressões de pensamento em forma de desenhos, fotos, cinema, vídeos, poemas, diários, artigos, livros, cartas, fragmentos de textos, entrevistas, conferências e mapas (MATOS e MIGUEL, 2020). Diante do vasto arquivo de vida-obra, encontramos (afecção) um texto de 1944, Os vagabundos eficazes (DELIGNY, 2018). Trata-se de um diário literário do que se passava no Centro de Observação e de Triagem (COT), no Sul da França, no período da Segunda Guerra Mundial. No COT, Deligny teve sua experiência como educador (instituteur) no Pavillon 3, como o denominou, lugar destinado a jovens e crianças delinquentes ou inadaptados socialmente.

Os vagabundos eficazes é um elogio ao desequilíbrio que as suas experimentações em educação trouxeram à institucionalização dos jovens delinquentes ${ }^{4}$. "Desequilíbrio?", pergunta Deligny (2018, p. 129). Ele mesmo responde, pela via da amizade com três errantes: "Pestalozzi, Rimbaud, Van Gogh, vocês - cujo desequilíbrio deixou marca gigantesca e cujos tesouros, ecos e a própria tenacidade nos maravilham - digam a ele o que significa ser "professor de escola"' (DELIGNY, 2018, p. 129). Significa vagar, vagar em errância exasperada para não calar a pergunta da educação, não calar a pergunta que desequilibra a atualidade do professor no presente: e a aula?

Assim, desde já, faz-se "vidente" nossa amizade por Deligny diante do elogio ao desequilíbrio, especialmente quando trazemos, para arqueo-montagem de aula, alguns conselhos e observações ${ }^{5}$ dos vagabundos eficazes. Como estamos problematizando e perguntando pela aula, a geopolítica do Pavillon 3 força-nos a vagabundear pela tela das visões e audições de um corpo normativo ${ }^{6}$ no uso da tela para aula síncrona. Tal problematização inspira-se em conselhos retirados de um tipo de espírito vagabundo.

1. O espírito vagabundo tem a posição da prática fatigante de dar fluxo à aula-vida quando nos diz: não dá para ignorar os mortos $^{7}$ vagando pela cidade. Expressar esse tipo de

\footnotetext{
${ }^{4}$ Nominação que o COT utilizava para identificar os jovens marginais levados àquele espaço. Deligny usa a nomenclatura delinquente para marcar sua ironia diante do sistema disciplinar institucional da infância e juventude nas políticas públicas daquele período.

${ }^{5}$ Em Os vagabundos eficaz̧es, Deligny (2018) escreve alguns conselhos e, também, séries de observações.

6 Instrução Normativa n. 21, de março de 2020. Altera a Instrução Normativa n. 19, de 12 de março de 2020, que estabelece orientações aos órgãos e entidades do Sistema de Pessoal Civil da Administração Pública Federal (SIPEC) quanto às medidas de proteção para enfrentamento da emergência de saúde pública de importância internacional decorrente do coronavírus (COVID-19).

${ }^{7}$ Refere-se ao número de pessoas mortas em decorrência do coronavírus (COVID-19).
} 
espírito permite-nos não ignorar a morte, faz com que acompanhemos o primeiro conselho de Deligny (2018, p. 126): “Boa sorte!”.

2. Quando estamos diante da tela online, arriscamo-nos a estar em presença de tal espírito, aquele que se faz da eficaz aula o lugar de "[...] criador de circunstâncias, assim é o educador a se debater com todas as inércias. Boa sorte" (DELIGNY, 2018, p. 126), novamente.

3. Considerando os dois conselhos anteriores, precisamos de boa sorte mesmo! Estamos todos em uma condição de inadaptados à atual geometria euclidiana do quadrado em três dimensões, tela das telas, cinética da velocidade ou/e a lentidão do sistema estado de corpo diante da tela-polegada, hora-aula online, vínculo com aula $=$ Meet, Teams, Zoom. Gerase a sala de aula: https://meet.google.com/hxd-xnzp-yan?pli=1\&authuser=0. Pelo Google Meet, registram-se imagens da aula síncrona. Estilo de imagens que não cessam de perguntar pela aula; saltam visões e audições que formam um combater as inércias mercadológicas sobre a aula.

4. Deligny, em uma carta, em 1946, dirige-se à União da Juventude Republicana Francesa ${ }^{8}$ para contar sobre seus modos de resistência à institucionalização dos corpos dos meninos no COT. Ele arquiva e registra os modos de tratamento a que esses meninos delinquentes são submetidos pela instituição educativa. Propõe uma cartografia da errância pelo aconselhamento como instituteur: "Se somos nós os delinquentes do Centro... somos os vagabundos eficazes" (DELIGNY, 2018, p. 67), e impomos o estilo do vagante como política de registrar traços do que se passa - no nosso problema, do que se passa em uma aula.

5. O estilo que vaga desequilibra a representação da aula. Pergunta-se: como funciona uma aula? Uma pergunta de estilo que (extra)vaga e expande o logos didático sobre a aula. Vagabundagem vagante pela experimentação do acontecimento de uma aula aumenta sua potência de agir inventivamente diante do que se passa nela. Espaço-temporal errante desequilibra a ordem da gravação das evidências científicas da aula remota online.

6. Em algumas das observações como instituteur, Deligny força a atenção pela tensão do gesto da voz. A voz não pode ser reduzida ao intelecto racionalista. A voz vibra nas pregas vitais. A voz ganha errância no espaço da aula. A voz desequilibra a falação. A voz espaçotemporal vaga pelas pausas dos silêncios da aula síncrona. A vida do que se passa nas aulas síncronas nos traz desequilíbrios vocais emitidos na errância da pergunta por como vivemos diante da pandemia.

7. "O educador (instituteur) sabe que é preciso se pôr em risco a fim de criar as condições para experiência vagabunda" (DELIGNY, 2018, p. 12), até porque a própria natureza do vagabundear é vagar; nela, tem-se a eficácia do desequilíbrio da institucionalização de prescrição educativa e escolar sobre o que é aula, ou seja, vagar pela aula desequilibra a ordem da institucionalização do ensino da vontade de verdade sobre como "dar" aula síncrona.

9. Apreende-se, dos vagabundos eficazes, o procedimento do vagar. A aula carrega o procedimento do espaço devagar vagando. Espaço-tempo vazio. Vagar ato de eco no vago. Percebe o vago que é vasto. Todo o vagabundear tem como eficácia andar ociosamente, flanar e perambular pela amizade proporcionada na infinitude do estranho. Flanar sempre

8 "Anos mais tarde, essa União tornou-se o Movimento da Juventude Comunista da França (MKCF)" (DELIGNY, 2018, p. 106). 
carrega a aula ao acaso e à necessidade. Vaga-se ao errar. O movimento cinético da aula produz sentido na duração intensiva dos movimentos: devagar, extravagar e extravagância.

10. Esse procedimento é parte dos conselhos que requerem o rigor de um modo de vida em meio ao elogio à stultitia no presente.

Figura 1: Os vagabundos eficazes

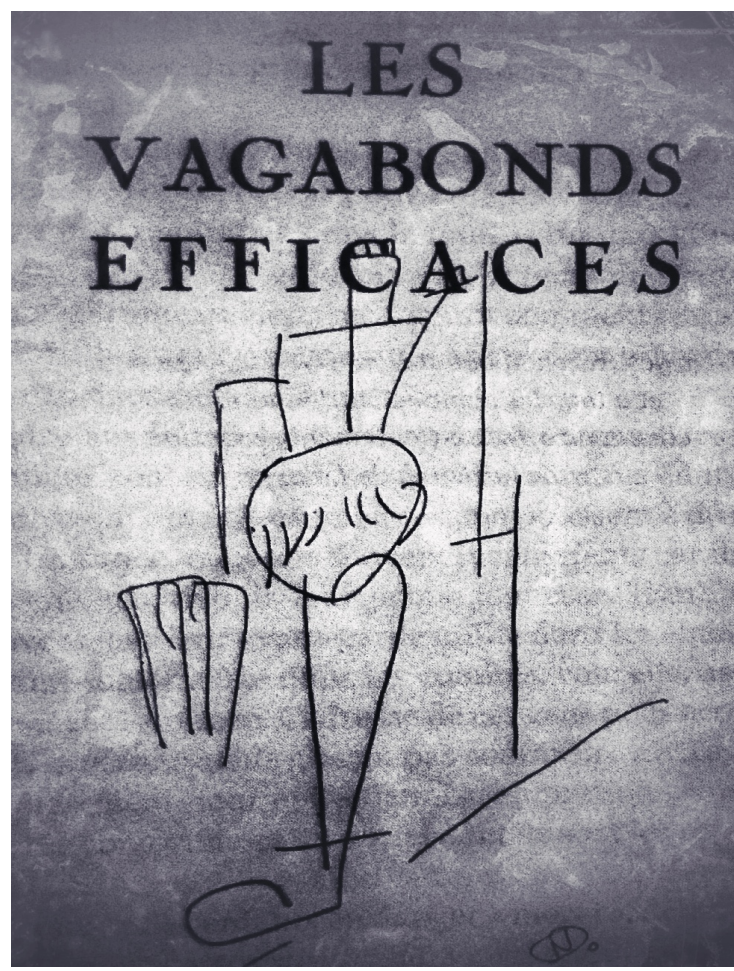

Fonte: Capa do texto retirada do livro Fernand Deligny Oeuvres (2007, p. 161); fotografia manipulada por Sônia Regina da Luz Matos, 2020.

\section{Conselhos de Sêneca por meio de cartas}

Há uma boniteza em dizer que o professor "dá" aula. Dar uma aula como uma oferenda, um convite, uma companhia, uma defesa. Sêneca (2018, p. 29), quando na antiguidade romana escrevia cartas, dizia em uma delas, dirigida a Lucílio, que uma carta poderia ser "[...] uma pequena oferenda do costume". Peter Sloterdijk (2018) também se referirá à filosofia como longas cartas escritas a amigos desconhecidos, talvez ainda nem nascidos, tal como uma possibilidade de amizade por meio da escrita: "[...] fazer amigos por meio do texto" (SZYMBORSKA, 2018, p. 7).

Sêneca escreveu cartas a Lucílio como um modo de equipar-se e como um modo de convidar o outro a cuidar de si. Há aproximadamente 2.000 anos o que teria Sêneca para nos dizer, a nós, submetidos ao Ministério dos Andares Bobos, a nós, professoras que damos aula em tempos de hastear a bandeira, de cantar o hino, de passar a boiada e de negligenciar as políticas públicas em educação de tantas formas impensáveis em meio a uma pandemia que mata mais de 100.000 pessoas no Brasil? "A burrice não é cômica”, já dizia Wislawa Szymborska (2011, p. 76).

Mas, como traz Sloterdijk (2018), essas escritas vindas de longe em formato de cartas talvez tenham algo a nos dizer ainda no presente. E elas nos chegam tal como um brinde, 
uma oferenda, uma conversação e um convite. Dizia Sêneca (2018, p. 24) sobre a amizade: "Por que arranjar então um amigo? Para ter alguém por quem se possa morrer, alguém que possa acompanhar ao exílio, alguém por quem me arrisque e ofereça à morte”. Aprendemos com Sêneca algumas máximas que nos ajudam a pensar o nosso presente e, apesar da forma romana por aconselhamento privado, pensamos que podemos fazer um roubo dessas máximas para pensarmos a multiplicidade da aula no presente em escolas e universidades.

1. A stultitia" é um perigo, o outro do cuidado de si, "o horror à vida". Essa agitação permanente não permite que nada dure o suficiente para que se tenha intimidade com o que se passa e para que concentremos o pensamento na ação. (SÊNECA, 2018; FOUCAULT, 2011). E no presente essa stultitia aparece espetacularizada e exposta nas narcísicas redes sociais, operando em bolhas de opiniões vulgares, orgulhosas de não terem argumento algum. Daí a necessidade de que alguém nos puxe para fora, não para suprir uma ignorância, mas para incidir sobre os modos como vivemos nossas vidas.

2. Cuidado com o perigo das maiorias. Das abelhas, pegamos a arte do recolhimento da leitura, e não a divisão hierárquica do trabalho por massificação. Todavia, entende-se que todos têm o direito de acessar os saberes que são um comum e de reivindicar a si mesmos (SÊNECA, 2018; FOUCAULT, 2011). Daí a importância de questionarmo-nos no presente, quando a condução das condutas passa fortemente pelas empresas e seu léxico pragmáticoutilitarista também em escolas e universidades.

3. O ócio (não a ociosidade) é necessário ao pensamento, à vida, à aula. O ócio, o outro do negócio. Hoje denunciado como inútil em nome de um pragmatismo instrumental de aplicabilidade imediata. Cabe pensar a aula como esse cultivo de si, que passa pela transmissão da cultura e pelo exercício do pensamento. Por isso, a aula não é um produto, mas pode ser um espaço para se aprender o cuidado com a vida. Preferir o importante ao útil (FOUCAULT, 2011; HAN, 2017).

4. A literatura e a filosofia podem ser armaduras importantes para o cultivo de si mesmo e do outro, podendo funcionar como aberturas de nossos próprios abscessos e para problematização desse sistema de endividamento de obrigação-recompensa (FOUCAULT, 2011). Podem ser um fármaco, um veneno, uma viagem, um estranhamento, mas que nos colocam em movimento, nos colocam a caminho, pensando não sobre o mundo, mas a partir do mundo.

5. Os espetáculos brutais e a poluição sonora seriam o outro de uma vida filosófica. Por isso, o perigo da "eloquência balofa", do "ruído" e do "artifício", o que talvez fosse um de nossos modos contemporâneos de escravidão aos outros e a nós mesmos. Sêneca cita Epicuro: “[...] eu não escrevi isso para muitos, mas sim para ti; contemplarmo-nos um ao outro é espetáculo suficiente" (SÊNECA, 2018, p. 17). O tempo presente tagarela tanto, que se esvazia cada vez mais de experiência, crendo-se incontestável - ainda mais o nosso, quando os medíocres são tomados como exemplos.

6. O ensino não se trata de opinião, meras notícias ou transmissão de informações, muito menos de entretenimento ou passatempo, mas de uma responsabilidade radical, de um tipo de crítica que valora o que muitos pensam ser perigoso: o exercício do pensamento.

\footnotetext{
9“[...] o estado no qual se acha quem não começou ainda o percurso da filosofia nem o trabalho da prática de si. Quem não teve ainda cuidados consigo encontra-se nesse estado de stultitia. Portanto, a stultitia é, se quisermos, o outro polo, em relação à prática de si. [...] O stultus é alguém que de nada se lembra, que deixa a vida correr, que não tenta reconduzi-la a uma unidade pela rememorização do que merece ser memorizado, e que não [dirige] sua atenção, seu querer, em direção a uma meta precisa e bem determinada. [...] Sua vida, sua existência passa, portanto, sem memória e nem vontade" (FOUCAULT, 2011, p. 118-119).
} 
Poderia se dar como que colocando o outro frente a frente consigo mesmo, justamente para arrancar-se de si e dos condicionalismos de ordem social e política. O que viria bem a calhar neste estado de exceção em que vivemos: um pensamento ético, ou melhor, a transformação da verdade em um ethos. Uma psicagogia ${ }^{10}$ (SÊNECA, 2018; FOUCAULT, 2011).

7. A filosofia e o ensino não se reduzem a uma habilidade técnica ou a uma abstração vazia, mas estão implicados com a vida, com a formação moral, podendo concernir a toda uma prática de si. Trata-se de mudar de vida ao invés de aprender doutrinas. Aliás, desconfiemos dos conformismos, das ideias prontas e do culto ao barato, como que fazendo escapes ao fascínio do conforto deste mundo administrado (SÊNECA, 2018; FOUCAULT, 2011; VEYNE, 2016). E como poderia uma aula ser um testemunho, um ato ínfimo, uma perplexidade, uma ruptura, uma inscrição, uma insurreição ética?

8. "Quem ensina se instrui". Sêneca falava mais do que do sábio, da sabedoria, do processo, de um modo de aplicação a si permanente. Preferia o exercício à identidade. E o ensino não se faz na acumulação de conhecimentos estéreis, mas com uma relação com os saberes que transformam a existência (SÊNECA, 2018; FOUCAULT, 2011, 2004). E não seria uma aula um espaço potente para também aprendermos a viver e a morrer?

9. “[...] um espírito bem formado consiste em ser capaz de parar [...]” (SÊNECA, 2018, p. 3). Não há como fazer boa digestão na aceleração; precisamos provar delicadamente, uma vez que a velocidade nos faz perder a única coisa que temos: o caminho, o instante. Talvez este seja outro modo de escravidão contemporâneo: essa super aceleração e essa passividade que vêm de não conseguirmos parar (HAN, 2017). Daí a necessidade de uma aula não "atirada", mas uma fala lenta que vai colocando coisas pelo caminho. Cada um pegue o quiser, o que puder, mas sempre apurando os ouvidos.

10. "Verifico, Lucílio, que não apenas me estou corrigindo, antes estou me transfigurando. Não garanto, nem sequer espero, que nada já reste em mim sem necessitar de mudança!" (SÊNECA, 2018, p. 12).

\footnotetext{
10“Chamemos, se quisermos, 'pedagógica' a transmissão de uma verdade que tem por função dotar um sujeito qualquer de aptidões, capacidades, saberes etc., que ele antes não possuía e que deverá possuir no final dessa relação pedagógica. Se chamarmos 'pedagógica', portanto, essa relação que consiste em dotar um sujeito qualquer de uma série de aptidões previamente definidas, podemos, creio, chamar 'psicagógica' a transmissão de uma verdade que não tem por função dotar um sujeito qualquer de aptidões, etc., mas modificar o modo de ser do sujeito a quem nos endereçamos" (FOUCAULT, 2011, p. 366).
} 
Figura 2: Andares Bobos

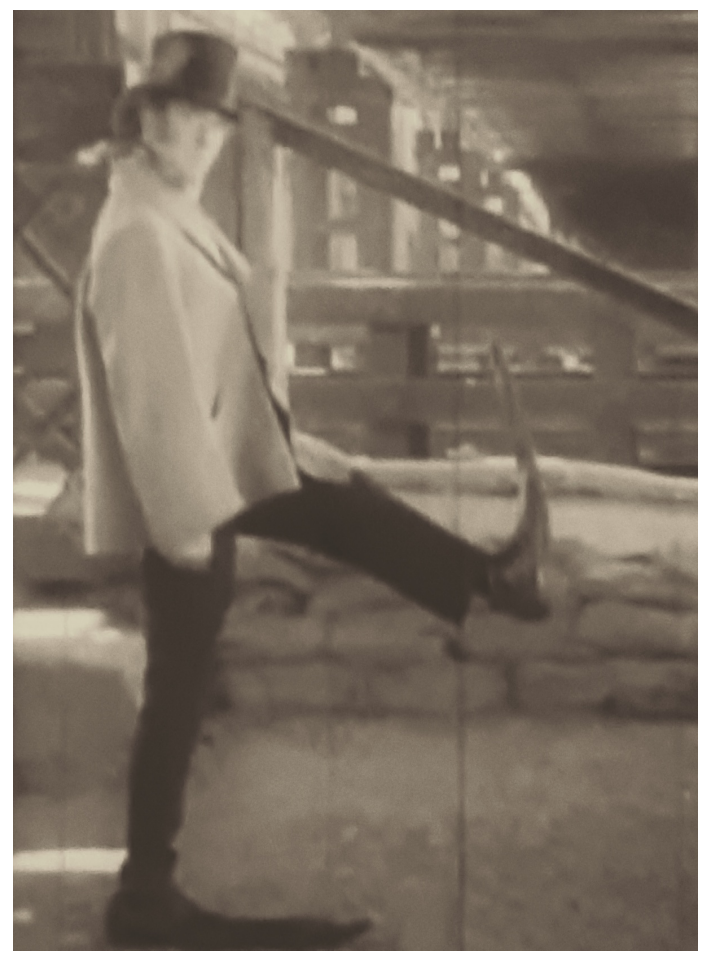

Fonte: Monty Python, fotografia manipulada por Sônia Regina da Luz Matos, 2020.

\section{CONSIDERAÇÕES FINAIS: "SOU, MAS NÃO TENHO QUE SER FILHA DA MINHA ÉPOCA ${ }^{11} \%$}

A atual problematização dos nossos modos de existência que toma a experiência da estranheza do presente direciona o texto e o tema deste, destacando a regularidade dos enunciados, perguntando pelos lugares no discurso para tal enunciação e para os meios institucionais, perguntando pela aula. Tal inquietação escorre até os tempos pandêmicos, na saúde e nas políticas públicas em educação, na estranheza de sermos arrastados para dentro de nossas casas, em home office. Vivemos a aula em movimento online e offline.

Ao perguntarmos pela aula, arriscamo-nos a deixar rastros discursivos de outro glossário, outra fotografia de aula, como palavra de ordem, a partir de um decreto em tempos de pandemia do novo coronavírus. Afirmamos, nestes rastros, os sintomas da aula que não pode ser representada. Afirmamos uma arque-montagem de aula, singularizando a feitura de capturas da experiência que vive a docência entre o acaso e o acontecimento; dito de outro modo, a docência que escapa das forças da didática geral, para nunca calar a pergunta pela aula e sua singularidade.

E perguntar pela singularidade da aula passaria, também, por um processo de desmontagem dos sintomas contemporâneos, como que os estranhando e perguntando pela produção de modos de existência em se tratando desse encontro que pode ser uma aula. Uma aula como o ato de criação das professoras para, de alguma maneira, ainda convidarmos os outros para pensarmos juntos, sem necessariamente pensar o mesmo. Uma aula como 
uma possibilidade de abertura para o mundo, para si e para os demais. Não um espaço para agradar alunos-clientes em seus interesses individuais tais como as existências nas redes sociais, mas para sermos ainda capazes de colocarmos outras perguntas.

Em tempos em que a vida nua vira números em tabelas coloridas na televisão; em tempos em que as mortalidades parecem não mais comover (SZYMBORSKA, 2011); em tempos de tamanha desigualdade social e educacional; em tempos em que o coletivo da sala de aula se espreme em uma tela, o que pode uma aula? "Me desculpem as grandes perguntas pelas respostas pequenas" (SZYMBORSKA, 2011, p. 50), retiradas dos conselhos de dois pensadores: Deligny e Sêneca, boas companhias.

\section{REFERÊNCIAS}

BENJAMIN, Walter. Experiência e pobreza. In: BENJAMIN, Walter. Magia e técnica, arte e política: ensaios sobre literatura e história da cultura. São Paulo: Brasiliense, 2012, p. 123-128. CORAZZA, Sandra. Como dar uma aula? Que pergunta é esta? In: MORAES, Vera Regina Pires (org.). Melhoria do ensino e capacitação docente: programa de atividades de aperfeiçoamento pedagógico. Porto Alegre, Ed. UFRGS, 1996, p. 57-63.

COMENIUS, Jan Amos. Didática Magna. São Paulo: Martins Fontes, 2002.

DELEUZE, Gilles. Foucault. Lisboa: Vega, 1998.

DELEUZE, Gilles. Curso sobre Spinoza. (Vincennes, 1978-1981). Fortaleza: EdUECE, 2009.

DELIGNY, Fernand. Os vagabundos eficazes. Operários, artistas, revolucionários, educadores. São Paulo: Edições n-1, 2018.

DELIGNY, Fernand. Fernand Deligny Oeuvres. Paris: Éditions L'Arachnéen, 2007.

DIÁRIO OFICIAL DA UNIÃO. Instrução Normativa n. 21, de março de 2020. Publicado em 17 mar. 2020, Edição 52, Seção 1, Página 17. Órgão Ministério da Economia, Secretaria Especial de Desburocratização, Gestão e Governo Digital, Secretaria de Gestão e Desempenho de Pessoal. Disponível em https://www.in.gov.br/en/web/dou/-/instrucaonormativa-n-21-de-16-de-marco-de-2020-248328867. Acesso em 8 ago. 2020.

DIDI- HUBERMAN, Georges. Sobrevivência dos vaga-lumes. Belo Horizonte: Editora UFMG, 2011.

FOUCAULT, Michel. A arqueologia do saber. Rio de Janeiro: Forense Universitária, 2002.

FOUCAULT, Michel. Nietzsche, a genealogia e a história. In: FOUCAULT, Michel. Microfísica do poder. Rio de Janeiro: Edições Graal, 2003, p. 15-37.

FOUCAULT, Michel. A escrita de si. In: FOUCAULT, Michel. Ética, sexualidade e política. Organização e seleção de textos de Manoel Barros Motta. Rio de Janeiro: Forense Universitária, 2004, p. 144-162.

FOUCAULT, Michel. A hermenêutica do sujeito: curso dado no Collège de France (1981-1982). São Paulo: Martins Fontes, 2011.

HAN, Byung-Chul. Sociedade do cansaço. Petrópolis: Vozes, 2017.

HEUSER, Ester Maria Dreher; AQUINO, Julio Groppa; CORAZZA, Sandra Mara. Apresentação. In: HEUSER, Ester Maria Dreher; AQUINO, Julio Groppa; CORAZZA, Sandra Mara (orgs.). Aula com... Em vias de uma didática da invenção. Cascavel, Paraná: 2018, p. 11-20.

HAYT, Regina Célia Cazaux. Curso de didática geral. São Paulo: Ática, 2006. 
LAVAL, Christian. A escola não é uma empresa: o neoliberalismo em ataque ao ensino público. São Paulo: Boitempo, 2019.

LAZZARATO, Maurizio. Signos, máquinas, subjetividades. São Paulo: Edições Sesc São Paulo: n-1 edições, 2014.

MATOS, Sônia Regina da Luz. Didática e suas forças vertiginosas. Conjecturas: filosofia e educação. Caxias do Sul, v. 14, n. 1, p. 93-134, jan./maio 2009. Disponível em file:///C:/Users/srlma/Downloads/6-24-1-PB.pdf. Acesso em 8 ago. 2020.

MATOS, Sônia Regina da Luz. Formação dos profissionais da educação: inflexionando um encontro. In: MATOS, Rosângela da Luz; PIMENTA, Lidia Boaventura; SANTOS, César Marques de Andrade (orgs.). Gestão, territórios e redes: formação dos profissionais da educação. Salvador: Edufba, 2016. p. 147-164.

MATOS, Sônia Regina da Luz; MIGUEL, Marlon. Conversação sobre Fernand Deligny e o aracniano. ETD - Educação Temática Digital. Campinas, v. 22, n. 2, p. 498- 516, abr./jun. 2020.

MELVILLE, Herman. Bartleby, o escriturário. (Uma história de Wall Street). Porto Alegre: L\&PM, 2008.

ORDINE, Nuccio. A utilidade do inútil: um manifesto. Rio de Janeiro: Zahar, 2016.

RODRIGUES, Elisandro; SCHULER, Betina. Montagem do pensamento e da escrita acadêmica em educação: conversações entre Deleuze e Didi-Huberman. ETD - Educação Temática Digital. Campinas, v. 21, n. 1, p. 23-46, jan./mar. 2019.

SÉNECA, Lúcio Aneu. Cartas a Lucílio. Lisboa: Fundação Calouste Gulbenkian, 2018.

SIBILIA, Paula. Redes e paredes: a escola em tempos de dispersão. Rio de Janeiro: Contraponto, 2012.

SLOTERDIJK, Peter. Regras para o parque humano: uma resposta à carta de Heidegger sobre o humanismo. São Paulo: Estação Liberdade, 2018.

SZYMBORSKA, Wislawa. Poemas. São Paulo: Companhia das Letras, 2011.

VEYNE, Paul. Sêneca e o estoicismo. São Paulo: Três Estrelas, 2016.

Submetido em agosto de 2020

Aprovado em novembro de 2020

\section{Informações das autoras}

Sônia Regina da Luz Matos

Professora do Programa de Pós-Graduação em Educação, Universidade de Caxias do Sul

E-mail:srlmatos@ucs.br

ORCID: https://orcid.org/0000-0002-3946-5628

Link Lattes: http://lattes.cnpq.br/7284092996786272

Betina Schuler

Programa de Pós-Graduação em Educação, UNISINOS 
E-mail: beschuler@unisinos.br

ORCID: https://orcid.org/0000-0002-2424-7601

Link Lattes: http://lattes.cnpq.br/5324014715865436 